\title{
Current Opinion on the Use of Magnetic Resonance Imaging in Staging Prostate Cancer: A Narrative Review
}

\author{
Jamie Michael', Kevin Neuzil², Ersan Altun ${ }^{3}$, Marc A Bjurlin $\mathbb{1}^{2,4}$ \\ 'University of North Carolina, School of Medicine, Chapel Hill, NC, USA; ${ }^{2}$ Department of Urology, University of North Carolina at Chapel Hill, \\ Chapel Hill, NC, USA; ${ }^{3}$ Department of Radiology, University of North Carolina at Chapel Hill, Chapel Hill, NC, USA; ${ }^{4}$ Lineberger Comprehensive \\ Cancer Center, University of North Carolina at Chapel Hill, Chapel Hill, NC, USA
}

Correspondence: Marc A Bjurlin, Associate Professor, Department of Urology, Lineberger Comprehensive Cancer Center, University of North Carolina, I0I Manning Drive, 2nd Floor, Chapel Hill, NC, USA, Email marc_bjurlin@med.unc.edu

\begin{abstract}
Accurate staging is critical for treatment planning and prognosis in men with prostate Cancer. Prostate magnetic imaging resonance (MRI) may aid in the staging evaluation by verifying organ-confined status, assessing the status of the pelvic lymph nodes, and establishing the local extent of the tumor in patients being considered for therapy. MRI has a high specificity for diagnosing extracapsular extension, and therefore may impact the decision to perform nerve sparing prostatectomy, along with seminal vesicle invasion and lymph node metastases; however, its sensitivity remains limited. Current guidelines vary significantly regarding endorsing the use of MRI for staging locoregional disease. For high-risk prostate cancer, most guidelines recommend cross sectional imaging, including MRI, to evaluate for more extensive disease that may merit change in radiation field, extended androgen deprivation therapy, or guiding surgical planning. Although MRI offers reasonable performance characteristics to evaluate bone metastases, guidelines continue to support the use of bone scintigraphy. Emerging imaging technologies, including coupling positron emission tomography (PET) with MRI, have the potential to improve the accuracy of prostate cancer staging with the use of novel radiotracers.
\end{abstract}

Keywords: prostate cancer, magnetic resonance imaging, staging

\section{Introduction}

It is estimated that approximately 250,000 men will be diagnosed with prostate cancer in 2021, along with an estimated 34,000 prostate cancer deaths in the United States. ${ }^{1}$ Prostate cancer varies dramatically in its aggressiveness, making accurate diagnosis, staging, and risk evaluation paramount to appropriate treatment. Previous risk stratification has focused on the use of parameters such as biopsy Gleason grade, clinical tumor stage, prostatic specific antigen (PSA) levels, incorporated into various nomograms, ${ }^{2,3}$ but defining risk categories remains an ongoing debate. Increasingly, magnetic resonance imaging (MRI) has been gaining popularity as a tool in disease staging and risk assessment.

Guidelines available differ significantly regarding the use of imaging for prostate cancer staging. Any new imaging modality incorporated into routine disease staging should distinguish local and metastatic or nodal disease and provide a reliable assessment of amenability to resection. In this review, we describe the current policy and guidelines surrounding the use of MRI and the current data in initial staging of local, regionalized, and metastatic disease. We further explore promising new advancements in MRI including the incorporation of PET and novel radiotracers.

\section{Policy and Guidelines}

MRI has been incorporated into policy and guidelines statements worldwide including the United States (US), Europe and the United Kingdom (UK) (Table 1). The 2017 American Urological Association (AUA) standard operating procedure for prostate MRI statement remarked that MRI has the potential to predict disease confined to the organ, that MRI should only be used in patients with predicted risk of lymph node metastases $>10 \%$, and that MRI can be incorporated into existing clinical staging 
Table I Summary of Recommendations for Use of MRI for Prostate Cancer Staging

\begin{tabular}{|c|c|c|}
\hline Association, Year & \multicolumn{2}{|c|}{ MRI Recommendations for Prostate Cancer Staging } \\
\hline AUA policy statement $2017^{6}$ & \multicolumn{2}{|c|}{$\begin{array}{l}\text {-MRI has potential to predict disease confined to the organ, EPE and SVI } \\
\text {-MRI should only be used in patients with predicted risk of LN mets }>10 \% \\
\text {-MRI can be incorporated into existing clinical staging systems }\end{array}$} \\
\hline AUA policy statement $2020^{7}$ & \multicolumn{2}{|c|}{$\begin{array}{l}\text {-When high quality, MRI has poor sensitivity but high specificity for detection of EPE when using secondar } \\
\text { markers such as bulge, capsule irregularity or capsular contact length } \\
\text {-MRI can be useful for treatment planning in men with presumed localized disease }\end{array}$} \\
\hline \multirow{4}{*}{$\begin{array}{l}\text { AUA/ASTRO/SUO guidelines } \\
2017^{10}\end{array}$} & Risk group & Recommendation \\
\hline & $\begin{array}{l}\text { Unfavorable intermediate risk localized } \\
\text { Grade group } 2 \text { with either PSA } 10-<20 \text { or clinical stage } \\
\text { T2b-c OR grade group } 3 \text { with PSA }<20\end{array}$ & $\begin{array}{l}\text { Stage with cross sectional imaging (CT or MRI) and } \\
\text { bone scintography }\end{array}$ \\
\hline & $\begin{array}{l}\text { High-risk localized prostate cancer } \\
P S A>20 \mathrm{ng} / \mathrm{mL} \text {, grade group } 4-5 \text { or clinical stage }>T 3\end{array}$ & $\begin{array}{l}\text { Stage with cross sectional imaging (CT or MRI) and } \\
\text { bone scintography }\end{array}$ \\
\hline & \multicolumn{2}{|c|}{$\begin{array}{l}\text {-MRI has improved accuracy to CT when imaging the prostate gland and avoids radiation exposure, however, } \\
\text { high-quality images are not available in every clinical setting }\end{array}$} \\
\hline \multirow[t]{6}{*}{ NCCN guidelines $2021^{8}$} & Risk group & Recommendation \\
\hline & $\begin{array}{l}\text { Very low risk } \\
\text { TIc, grade group I, PSA }<10 \mathrm{ng} / \mathrm{mL} \text {, fewer than } 3 \\
\text { positive biopsy cores, } \leq 50 \% \text { cancer in each core, and PSA } \\
\text { density }<0.15 \mathrm{ng} / \mathrm{mL} / \mathrm{g}\end{array}$ & $\begin{array}{l}\text { MRI can be used to establish candidacy for active } \\
\text { surveillance when combined with biopsy }\end{array}$ \\
\hline & $\begin{array}{l}\text { Low risk } \\
T I-T 2 a \text {, grade group I and PSA }<10 \mathrm{ng} / \mathrm{mL}\end{array}$ & $\begin{array}{l}\text { MRI can be used to establish candidacy for active } \\
\text { surveillance when combined with biopsy }\end{array}$ \\
\hline & $\begin{array}{l}\text { Intermediate risk } \\
\text { No high risk features with } T 2 \mathrm{~b}-\mathrm{T} 2 \mathrm{c} \text {, grade group 2-3, } \\
\text { and/or PSA } 10-20 \mathrm{ng} / \mathrm{mL}\end{array}$ & $\begin{array}{l}\text { MRI if nomograms predict }>10 \% \text { probability of } L N \\
\text { involvement }\end{array}$ \\
\hline & $\begin{array}{l}\text { High risk } \\
\text { T3a, grade group } 4-5 \text { or PSA }>20 \mathrm{ng} / \mathrm{mL}\end{array}$ & MRI for staging in all patients \\
\hline & $\begin{array}{l}\text { Very high risk } \\
\text { T3b-T4, primary Gleason } 4 \text { or }>4 \text { cores with Grade } \\
\text { Group } 4-5\end{array}$ & MRI for staging in all patients \\
\hline \multirow{4}{*}{$\begin{array}{l}\text { EAU/EANM/ESTRO/ESUR/SIOG } \\
\text { guidelines } 2020^{\circ}\end{array}$} & Risk group & Recommendation \\
\hline & $\begin{array}{l}\text { High-risk localized } \\
P S A>20 \mathrm{ng} / \mathrm{mL} \text { or ISUP grade } 4 / 5 \text { or } c T 2 c\end{array}$ & $\begin{array}{l}\text { Cross-sectional abdominopelvic imaging strongly } \\
\text { recommended for staging }\end{array}$ \\
\hline & $\begin{array}{l}\text { Locally advanced } \\
\text { cT3-4 or } \mathrm{cN}+\end{array}$ & $\begin{array}{l}\text { Cross-sectional abdominopelvic imaging strongly } \\
\text { recommended for staging }\end{array}$ \\
\hline & \multicolumn{2}{|c|}{-Prebiopsy MRI for local staging information only weakly recommended } \\
\hline NICE recommendations $2019^{27}$ & \multicolumn{2}{|c|}{-Recommend against offering MRI to patients who are not going to be able to have radical treatment } \\
\hline
\end{tabular}

systems. ${ }^{4-6}$ In a 2020 updated statement, the AUA also stated that MRI has poor sensitivity but high specificity for detection of extraprostatic extension (EPE) only when images are high-quality. ${ }^{7}$ Similar to the AUA policy statements, the National Comprehensive Cancer Network (NCCN) guidelines in 2021 recommend MRI for intermediate risk patients if risk of lymph node (LN) metastases is $>10 \%{ }^{8}$ Furthermore, the NCCN guidelines recommend MRI for staging in all patients with high risk or very high risk prostate cancer. The AUA/ American Society for Radiation Oncology (ASTRO)/Society of Urologic Oncology 
(SUO) guidelines in 2017 and the European Association of Urology (EAU)/European Association of Nuclear Medicine (EANM)/European Society for Radiotherapy and Oncology (ESTRO)/European Society of Urogenital Radiology (ESUR)/ International Society of Geriatric Oncology (SIOG) guidelines in 2020 also recommend cross-sectional imaging for high-risk patients, however these organizations do not specify between computed tomography (CT) and MRI. ${ }^{9-15}$ Similar to the AUA policy statement, the AUA/ASTRO/SUO guidelines also highlight the importance of high-quality images, stating also that highquality images are not available in every clinical setting. This marks a significant limitation of MRI for use in detection and staging in prostate cancer. ${ }^{16}$

\section{MRI Technical Considerations}

MRI of the prostate gland should be done with or without endorectal coil at 1.5 tesla (T) if one is using a state-of-the-art 1.5 T scanner with multichannel surface coils, and with or without endorectal coil at 3.0 T based on Prostate Imaging Reporting \& Data System (PIRADS) v2.1. The use of anti-peristaltic agents before the examination is not specifically recommended on PIRADS v2.1 although this could also be employed to decrease the peristalsis, particularly if no endorectal coil is used, and this may particularly improve the image quality of T2 turbo spin echo (TSE) sequences. Susceptibility artifacts from the rectal gas is also a significant limitation for diffusion weighted imaging (DWI) and this could be eliminated with the placement of a rectal tube before the examination to decompress and evacuate the rectal gas although this has not been recommended based on PIRADS v2.1. The abstinence from sex has not been specifically recommended based on PIRADS v2.1. The presence of unilateral or bilateral hip implants also make DWI sequences nondiagnostic due to susceptibility artifacts. Susceptibility artifacts from unilateral hip implants usually do not significantly affect the assessment of prostate gland on T2 TSE sequences. However, the presence of bilateral implants may impair the image quality of T2 TSE sequence for the assessment of prostate gland to some extent which may significantly affect the assessment of prostate gland. These artifacts also impair the image quality on post-gadolinium T1-weighted 3D-GE (three dimensional gradient echo) sequences including dynamic contrast enhanced MRI sequences and this limits the assessment of lymph nodes and prostate gland, respectively. T2-weighted SSETSE (single shot echo train spin echo) sequence is relatively resistant to susceptibility artifacts and can be used for the assessment of lymph nodes. All these artifacts limit staging of prostate cancer on MRI including EPE, seminal vesicle invasion (SVI), neurovascular bundle involvement and lymph node involvement. Therefore, techniques limiting the development of these artifacts improve the image quality and improve staging of prostate cancer.

The use of intravenous (IV) contrast is also not essential for the determination of EPE, SVI or neurovascular bundle involvement although it may be important for the identification of bone metastases and lymph node metastases. Various abbreviated protocols have recently been proposed in an attempt to reduce time, costs, and patient discomfort of multiparametric (mp) MRI. ${ }^{17}$ Specifically, biparametric (bp) MRI removes the dynamic contrast-enhanced (DCE) sequence. Various studies have demonstrated that bpMRI has comparable accuracy to mpMRI for the detection of ECE. ${ }^{17-19}$ However, some found that mpMRI was superior for SVI detection. ${ }^{19}$

MRI technique employed should be in consistent with PIRADS v2.1 in order to keep MRI examinations standard among all institutions. The critical technical considerations include the employment of $3.0 \mathrm{~mm}$ slice thickness without any gap and with sufficient spatial resolution using a small field of view for T2 TSE, and employment of 3 versus $4 \mathrm{~mm}$ slice thickness without any gap and with sufficient spatial resolution using a small field of view for DWI per PIRADS v2.1. Similarly, high temporal resolution with relatively low spatial resolution DCE with $3 \mathrm{~mm}$ slice thickness without any gap is also very important for good image quality. The use of high $b$ values is also essential for the identification of clinically significant cancer per PIRADS v2.1. It has been previously shown that adherence to these technical guidelines is heterogenous. Lack of standardization represents a potential limitation to the accuracy of MRI and previous studies have endorsed greater diffusion of the PIRADS guidelines. ${ }^{20}$

High spatial and contrast resolution imaging techniques are needed to improve the accuracy of MRI in the diagnosis of prostate cancer and local staging of prostate cancer including the identification of EPE, neurovascular bundle involvement and bladder neck involvement. Novel techniques and approaches which has the potential to improve spatial and contrast resolution should be employed to improve the image quality of T2-weighted, DWI and DCE sequences on all three planes. The use of higher spatial and contrast techniques could improve the assessment of extra-prostatic disease particularly at the apex and base in all planes. Additionally, new imaging techniques including but not limited T1/T2 mapping, novel DWI techniques and luminal water imaging may also contribute to local staging although there is still not sufficient data in the literature. ${ }^{21}$ 


\section{Reporting Standards}

When MRI began to emerge as a promising imaging modality for prostate tumor identification, risk stratification and biopsy guidance, clinicians recognized the need for a standardized reporting system. ${ }^{22}$ In 2019 the PI-RADS ${ }^{23}$ system version 2.1 was published. This system details score criteria for each MRI sequence, and explains how to assign an overall score depending on sequences available and lesion zone. ${ }^{24} \mathrm{DWI}$ sequences are recommended as the primary determining sequences for peripheral zone lesions and $\mathrm{T} 2 \mathrm{~W}$ sequences for transition zone lesions.

The PI-RADS system has a number of limitations, including low variable positive predictive value. ${ }^{25}$ Given these limitations, the UK MRI consensus meeting released recommendations that physicians use the Likert scale for interpretation of MRIs until further evolution of the PI-RADS scoring system. ${ }^{26}$ Similarly, the recently revised NICE guidelines have recommended the use of the Likert scale for scoring of prostatic MRI. ${ }^{27}$ The Likert scale was in use before the introduction of the PI-RADS classification. It is similarly a 5-point scale to rate probability of cancer on MRI. Unlike the PI-RADS system it takes into account clinical information such as age, PSA, gland volume and family history. In addition, it does not establish a dominant sequence for prostate lesions, allowing for more flexibility towards the modification of overall score when particularly suspicious findings are noted. Furthermore, the PI-RADS system separates a score of 4 and 5 by lesion size $>1.5 \mathrm{~cm}$. In contrast, the Likert scale uses reader confidence to differentiate these two categories. Finally, PI-RADS was developed specifically for pre-biopsy evaluations while Likert can be applied to any clinical scenario and, therefore, may be more appropriate for prostate cancer staging following biopsy. ${ }^{28}$ Studies comparing Likert to the multiple versions of the PI-RADS system have mainly demonstrated equivalence. ${ }^{29,30}$ However, the Likert score is more subjective in interpretation compared to PI-RADS. Therefore, the Likert assessment allows for more flexibility and relies more on reader intuition. ${ }^{31}$ For experienced radiologists, the Likert scale may be Associated with increased detection of clinically significant prostate cancers. ${ }^{32}$

\section{Local Staging}

Extra-prostatic extension (T3a), seminal vesicle invasion (T3b) and local invasion to adjacent structures (T4) carry worse prognosis and higher risk of positive surgical margins and biochemical recurrence following primary therapy. Knowledge of local advancement of disease can impact extent of surgical field, success of surgical treatment and consideration of alternative therapies. Therefore, accurate clinical staging has important implications for treatment planning and patient outcomes.

During treatment of localized prostate cancer with radical prostatectomy, a high risk of locally advanced disease, or EPE, is a usual contraindication for nerve sparing. ${ }^{9}$ Traditionally, EPE is evaluated by nomograms including clinical variables like PSA, DRE and Gleason score at biopsy (Partin tables, Memorial Sloan Kettering Cancer Center [MSKCC]). ${ }^{33}$ However, these methods have been shown to be inferior to MRI and offer no information about location and extent of EPE. ${ }^{4,34}$ With improved localization of EPE, MRI can theoretically help direct nerve sparing decisions for surgeons. In 2018, Schiavina et al investigated this hypothesis by analyzing the surgical plan of nerve-sparing based on clinical data and then after MRI in 137 robotic assisted robotic prostatectomy (RP) patients. ${ }^{35}$ The authors demonstrated that MRI led surgeons to change their plan in $46.7 \%$ of individuals, without compromising rate of positive surgical margins. A study in 2012 investigating the role of MRI on neurovascular bundle management conducted by Panebianco et al had similar findings. The authors observed that MRI was able to confirm appropriateness of bilateral nerve sparing surgery or guide a change to unilateral or no nerve sparing, with a rate of positive margins low at $3.8 \%{ }^{36}$ Similarly, in a 2019 study of 1037 men undergoing robotic assisted RP, authors demonstrated that undergoing MRI was Associated with increased risk of a non-nerve sparing approach, with a risk ratio of 1.84 . Furthermore, they found rates of positive surgical margins were $26.7 \%$ in their preoperative MRI group compared to $33.7 \%$ in their non-MRI group. ${ }^{37}$ Some studies, however, have failed to demonstrate an improvement in positive surgical margin rate with pre-operative MRI. In 2015, Rud et al investigated the ability of MRI to reduce rates of positive surgical margins. In this study, authors observed a rate of positive surgical margin of $23 \%$ in the non-MRI group and $19 \%$ in the MRI group with a non-significant p-value of 0.4. ${ }^{38}$ In conclusion, MRI has the potential to improve functional outcomes. ${ }^{39}$

\section{Staging of T3a Disease}

A 2016 meta-analysis of 75 total studies found that pooled data for EPE showed sensitivity and specificity of 57\% and 91\% respectively, concluding that MRI has high specificity but poor sensitivity for local prostate cancer staging 
Table 2 Summary of MRI Performance Characteristics for Detection of T3a, T3b and T4 Disease

\begin{tabular}{|c|c|c|c|c|c|c|c|}
\hline Publication & Study Design & Year & Sensitivity & Specificity & PPV & NPV & Accuracy \\
\hline \multicolumn{8}{|l|}{ Staging T3a disease } \\
\hline de Rooij et $\mathrm{al}^{40}$ & Meta-analysis & 2016 & $57-68 \%$ & $91 \%$ & $n / a$ & $\mathrm{n} / \mathrm{a}$ & $\mathrm{n} / \mathrm{a}$ \\
\hline Boesen et $\mathrm{al}^{41}$ & Prospective & 2015 & $6 I-74 \%$ & $77-88 \%$ & $n / a$ & $\mathrm{n} / \mathrm{a}$ & $\mathrm{n} / \mathrm{a}$ \\
\hline Muehlmatter et $\mathrm{al}^{81}$ & Retrospective & 2019 & $28 \%$ & $47 \%$ & $n / a$ & $\mathrm{n} / \mathrm{a}$ & $\mathrm{n} / \mathrm{a}$ \\
\hline Boesen et $\mathrm{al}^{82}$ & Prospective & 2017 & $81 \%$ & $78 \%$ & $\mathrm{n} / \mathrm{a}$ & $\mathrm{n} / \mathrm{a}$ & $79 \%$ \\
\hline Bai et a $\left.\right|^{83}$ & Systematic review & 2019 & $80.5 \%$ & $69.1 \%$ & $n / a$ & $\mathrm{n} / \mathrm{a}$ & $\mathrm{n} / \mathrm{a}$ \\
\hline Zhang et $\mathrm{al}^{84}$ & Meta-analysis & 2019 & $55 \%$ & $87 \%$ & $n / a$ & $n / a$ & $\mathrm{n} / \mathrm{a}$ \\
\hline Tirumani et $\mathrm{al}^{85}$ & Meta-analysis & 2020 & $\begin{array}{l}\text { ERC: } 53 \% * \\
\text { No ERC: } 34 \%\end{array}$ & $\begin{array}{l}\text { ERC: } 95 \% \\
\text { No ERC: } 95 \%\end{array}$ & $\mathrm{n} / \mathrm{a}$ & $\mathrm{n} / \mathrm{a}$ & $\mathrm{n} / \mathrm{a}$ \\
\hline Davis et al ${ }^{86}$ & Prospective & 2016 & $12.5 \%$ & $93.1 \%$ & $36.4 \%$ & $77.0 \%$ & $\mathrm{n} / \mathrm{a}$ \\
\hline Cerantola et $\mathrm{al}^{87}$ & Retrospective & 2013 & $35 \%$ & $90 \%$ & $57 \%$ & $79 \%$ & $62 \%$ \\
\hline Dominguez et a ${ }^{88}$ & Retrospective & 2018 & $54.9 \%$ & $90.9 \%$ & $81 \%$ & $74.1 \%$ & $76 \%$ \\
\hline Gaunay et $\mathrm{al}^{89}$ & Retrospective & 2017 & $58.3 \%$ & $97.8 \%$ & $93.3 \%$ & $81.5 \%$ & $\mathrm{n} / \mathrm{a}$ \\
\hline Feng et $\mathrm{al}^{90}$ & Retrospective & 2015 & $84.6 \%$ & $87.2 \%$ & $66.7 \%$ & $94.9 \%$ & $\mathrm{n} / \mathrm{a}$ \\
\hline Hegde et $\mathrm{al}^{91}$ & Retrospective & 2013 & $\mathrm{n} / \mathrm{a}$ & $\mathrm{n} / \mathrm{a}$ & $\mathrm{n} / \mathrm{a}$ & $\mathrm{n} / \mathrm{a}$ & $75 \%$ \\
\hline Lee et $\mathrm{al}^{92}$ & Retrospective & 2017 & $54.5 \%$ & $80.5 \%$ & $\mathrm{n} / \mathrm{a}$ & $\mathrm{n} / \mathrm{a}$ & $\mathrm{n} / \mathrm{a}$ \\
\hline Lee et $\mathrm{al}^{93}$ & Retrospective & 2017 & $39 \%$ & $56 \%$ & $45 \%$ & $50 \%$ & $\mathrm{n} / \mathrm{a}$ \\
\hline Toner et $\mathrm{a}^{94}$ & Retrospective & 2017 & $29 \%$ & $94 \%$ & $\mathrm{n} / \mathrm{a}$ & $\mathrm{n} / \mathrm{a}$ & $\mathrm{n} / \mathrm{a}$ \\
\hline \multicolumn{8}{|c|}{ Staging of T3b disease } \\
\hline de Rooij et $\mathrm{al}^{40}$ & Meta-analysis & 2016 & $58 \%$ & $96 \%$ & $\mathrm{n} / \mathrm{a}$ & $\mathrm{n} / \mathrm{a}$ & $\mathrm{n} / \mathrm{a}$ \\
\hline Grivas et $\mathrm{al}^{54}$ & Retrospective & 2018 & $75.9 \%$ & $94.7 \%$ & $62 \%$ & $97 \%$ & $\begin{array}{l}\text { Reader's expertise } \\
\text { improved accuracy }\end{array}$ \\
\hline Riney et $\mathrm{al}^{55}$ & Retrospective & 2018 & $30.3-56.1 \%$ & $80.2-88.6 \%$ & $37.7-66.1 \%$ & $74.4-83.6 \%$ & $66.1-79.4 \%$ \\
\hline Muehlmatter et $\mathrm{al}^{81}$ & Retrospective & 2019 & $35 \%$ & $50 \%$ & $n / a$ & $\mathrm{n} / \mathrm{a}$ & $\mathrm{n} / \mathrm{a}$ \\
\hline Tirumani et $\mathrm{al}^{85}$ & Meta-analysis & 2020 & $\begin{array}{l}\text { ERC: } 52 \% \\
\text { No ERC: } 45 \%\end{array}$ & $\begin{array}{l}\text { ERC: } 92 \% \\
\text { No ERC: } 94 \%\end{array}$ & $n / a$ & $\mathrm{n} / \mathrm{a}$ & $\mathrm{n} / \mathrm{a}$ \\
\hline Hegde et al ${ }^{91}$ & Retrospective & 2013 & $\mathrm{n} / \mathrm{a}$ & $n / a$ & $n / a$ & $\mathrm{n} / \mathrm{a}$ & $95 \%$ \\
\hline Dominguez et a $\left.\right|^{88}$ & Retrospective & 2018 & $19.1 \%$ & $100 \%$ & $100 \%$ & $76.1 \%$ & $77.3 \%$ \\
\hline Lee et $\mathrm{al}^{92}$ & Retrospective & 2017 & $43.8 \%$ & $95.4 \%$ & $\mathrm{n} / \mathrm{a}$ & $78.9 \%$ & $\mathrm{n} / \mathrm{a}$ \\
\hline Lee et $\mathrm{al}^{93}$ & Retrospective & 2017 & $33 \%$ & $95 \%$ & $50 \%$ & $91 \%$ & $\mathrm{n} / \mathrm{a}$ \\
\hline \multicolumn{8}{|c|}{ Staging of T4 disease } \\
\hline Leibovici et $\mathrm{al}^{95}$ & Prospective & 2005 & $23.4-83.3 \%$ & $76.8-100 \%$ & $\mathrm{n} / \mathrm{a}$ & $\mathrm{n} / \mathrm{a}$ & $59.3-93.2 \%$ \\
\hline
\end{tabular}

Abbreviation: *ERC, endorectal coil. 
(Table 2). ${ }^{40}$ EPE sensitivity was not improved by endorectal coil use, but a sub-analysis of higher field strengths (3T), showed improved sensitivity of $68 \%,{ }^{40}$ demonstrating a potential area for improvement.

The PI-RADS v2.1 criteria briefly describe what should be assessed for EPE by radiologists on MRI. ${ }^{24}$ Specifically, PI-RADS v2.1 proposes factoring in capsular abutment, capsular irregularity, spiculation or retraction, neurovascular bundle asymmetry or thickening, obliteration of the recto-prostatic angle, tumor-capsular contact $>10 \mathrm{~mm}$, bulge or loss of capsule and measurable extracapsular disease when determining risk of EPE. However, there is little guidance regarding how these findings should be used or their accuracy. Studies evaluating the performance characteristics of the PI-RADS v2 classification system for the detection of EPE have found that sensitivity and specificity of PIRADS v2.1 for detection of EPE was $81 \%$ and $78 \%$ respectively. ${ }^{41}$ In 2012, the ESUR published their MR protocol guidelines. ${ }^{23}$ In regards to EPE, they suggested a 45 minute protocol, preferably with ERC, including T2W images at 1.5T, 3T images, DWI and DCE. Criteria for EPE were detailed as abutment, irregularity, neurovascular bundle thickening, bulge, loss of capsular enhancement, measurable EPE disease and obliteration of the recto-prostatic angle. Studies investigating these criteria have found moderate accuracy when using these ESUR/PI-RADS technical guidelines for the detection of EPE. $^{42}$

Although PIRADS v2.1 describes some common findings associated with EPE, it does not distinguish relative importance of different predictive values. To address these shortcomings, Mehralivand et al developed their own grading system for the assessment of EPE using MRI. ${ }^{43}$ This grading system is as follows: curvilinear contact length of $1.5 \mathrm{~cm}$ or capsular bulge and irregularity are grade 1 , both features together are grade 2, frank capsular breach is grade 3 . In a study of 553 participants, the authors found that higher grade category was associated with higher risk of EPE but that clinical features (PSA and Gleason) combined with their grading system predicted pathologic EPE better than imaging alone with area under the curve (AUC) of 0.81 and 0.77 respectively. A 2020 study compared this grading system to the Likert scale $^{44}$ which demonstrated that the Mehralivand EPE grade and EPE Likert had equivalent diagnostic performance, but that the Likert scale does not rely on any specific criteria and is very subjective.

Length of tumor contact at capsule can be a particularly helpful measurement when determining risk of EPE, which can be seen by its inclusion in both aforementioned systems, however there is still lack of data about its predictive value. Previous studies indicate length of contact has good accuracy and inter-reader agreement. ${ }^{45-48}$ Rosenkrantz et al reported that inter-reader agreement was 0.7 for assessments based on length of contact and 0.49-0.59 for subjective assessments. ${ }^{46}$ There remains disagreement on the exact threshold to use for this criterion. The PIRADS v2 guidelines recommend using $>10 \mathrm{~mm}$, while other sources vary from $6-20 \mathrm{~mm} .{ }^{47}$ Factors such as technical method of measurement (linear vs curvilinear) and pretest probability can, in part, explain this variation. One study found that for high-grade tumors ( $>$ Gleason $4+3$ ), positive predictive value of $\geq 5 \mathrm{~mm}$ of contact was $90.9 \%$ versus positive predictive value of $90.4 \%$ for $\geq 12.5 \mathrm{~mm}$ for lower grade tumors. ${ }^{45}$

High image quality without motion artifacts is essential for identification of EPE. ${ }^{49}$ One area of potential improvement may be 3D T2W imaging versus 2D. In a study comparing the two, Caglic et al found that 3D T2W improved sensitivity from $65 \%$ to $75 \%$ while maintaining similar specificity for detection of EPE lesions $(p=0.058) .{ }^{45}$ In a study of capsular contact by MRI sequence, Woo et al found that optimal threshold value for predicting EPE was $>14 \mathrm{~mm}$ for T2W images, $>13 \mathrm{~mm}$ for apparent diffusion coefficient (ADC), $>12 \mathrm{~mm}$ for DCE and $>14 \mathrm{~mm}$ for greatest of all 3 sequences. The authors found that greatest length of capsular contact yielded the greatest AUC (0.895) but performance was relatively equivalent among different sequences. ${ }^{48}$ Finally, ADC has previously been inversely associated with probability of clinically significant prostate cancer. In the investigation of EPE, Rud et al demonstrated that tumors with low ADC $\left(<89 \times 10^{-5} \mathrm{~mm}^{2} / \mathrm{s}\right)$ had $50 \%$ probability of EPE on histopathology. ${ }^{50}$ Conversely, a study by Lim et al did not find a correlation between mean $\mathrm{ADC}$ and probability of subsequent $\mathrm{EPE}^{51}$ (Figures 1-3).

In conclusion, MRI has the potential to detect EPE, which has implications for surgical planning and patient outcomes. However, previous studies have shown high specificity but moderate sensitivity, underscoring how results should be interpreted with caution. Various MRI criteria have been evaluated for the prediction of EPE after surgery and new grading systems are emerging. Studies show that incorporating clinical data into any grading system could improve performance characteristics. 


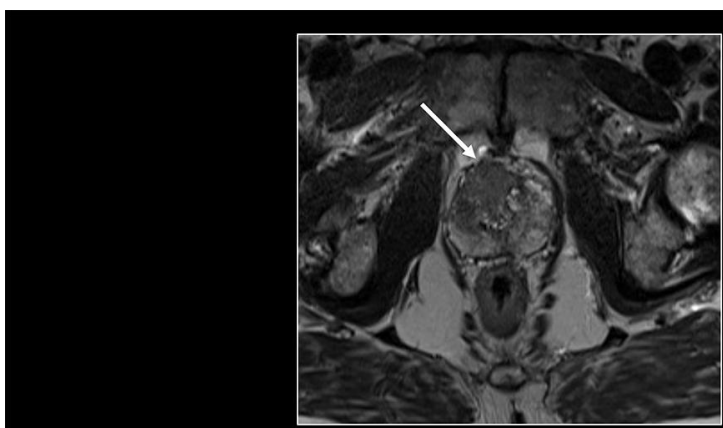

A

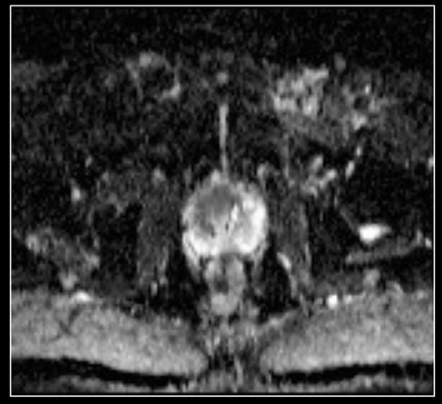

C

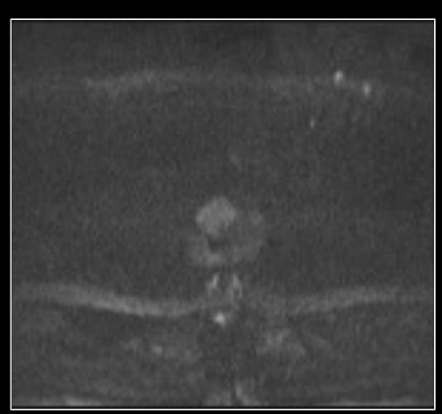

B

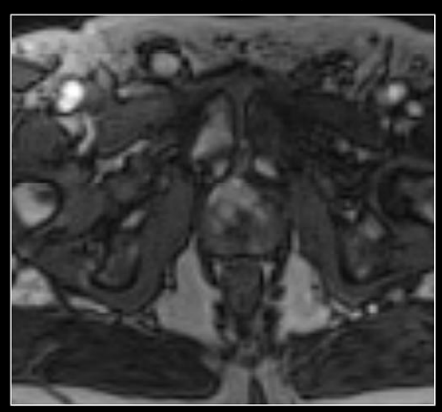

D

Figure I Transverse T2-weighted TSE (A), DWI (B), ADC map (C) and TI-weighted DCE (D) demonstrate a PIRADS 5 lesion predominantly located in the right and anterior transitional zone. The lesions shows very low T2 signal, high DWI signal on high b value DWI sequence and low ADC signal suggestive of diffusion restriction, and increased early enhancement compared to the background prostate. There is evidence of extracapsular extension (arrow, a) anteriorly with associated significant bulging of the lesion into the periprostatic fat anteriorly. These findings are suggestive of T3a disease. The lesion is a Gleason $3+4$ tumor based on histopathology.

\section{Staging of T3b Disease}

The involvement of one or both seminal vesicles (SV) by prostate cancer has important clinical significance and denotes stage T3b. SVI is associated with higher risk of biochemical recurrence and lymph node metastases. ${ }^{52}$ Therefore, if detected pre-surgically, SVI has potential to change therapeutic plan. Similar to EPE assessment, preoperative detection of SVI is traditionally performed using clinical risk assessment tools (Kattan nomogram and Partin tables). Previous studies comparing MRI to these nomograms have found that MRI alone, or in addition to standard clinical nomograms, may provide additional predictive value for SVI. ${ }^{4,53}$

Prior studies have investigated the performance characteristics of MRI for the detection of SVI. In a meta-analysis, Rooij et al determine pooled sensitivity and specificity for SVI were $58 \%$ and $96 \%$ respectively. ${ }^{40}$ A retrospective review in 2018 of 527 patients who underwent 3T MRI found similar results with sensitivity, specificity, positive predictive value (PPV) and negative predictive value (NPV) for SVI detection by MRI of $75.9 \%, 94.7 \%$, 62\% and 97\% respectively $^{54}$ (Table 2). In a study of 233 men undergoing prostatectomy at a tertiary referral center, researchers found that SVI interpretation was more uniform than EPE, with initial MRI interpretation and reread yielding similar sensitivity, specificity, PPV, NPV and accuracy. ${ }^{55}$

Several pathways for prostate cancer invasion into the seminal vesicles have been previously described. ${ }^{56}$ Type I is direct spread along the ejaculatory duct complex. Type II is spread outside of the prostate, through the capsule. Type III is isolated deposits of cancer into the seminal vesicle with no evidence of direct spread from the prostate. Mechanism of spread may have implications for appearance on MRI. Type I invasion causes SV expansion with a low signal intraluminal mass with focal or diffuse wall thickening. In contrast, type II spread may appear as obliteration of the angle between the base of the prostate and the $\mathrm{SV}^{56}$ (Figure 3).

Studies have shown that for the detection of SVI, MRI plus clinical variables outperforms MRI or clinical variables alone. In a 2017 study of 501 patients with preoperative MRI, Morlacco et al found that the AUC for Partin tables + MRI 


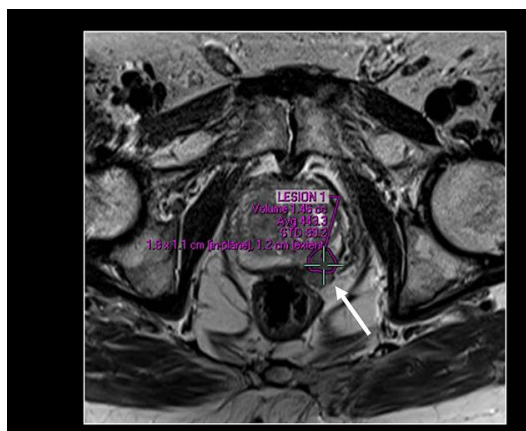

A

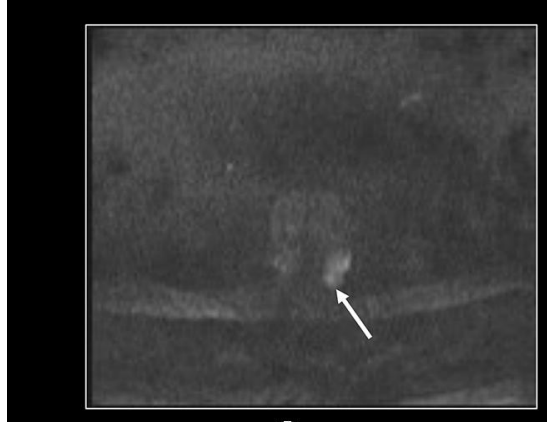

C

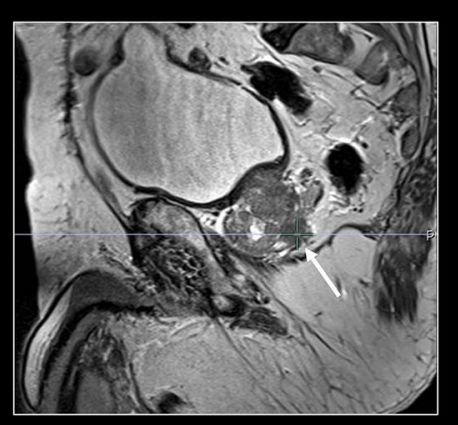

B

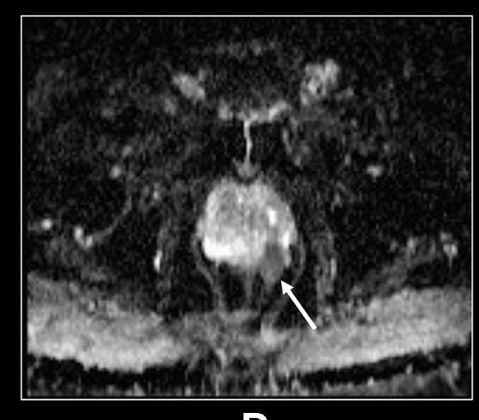

D

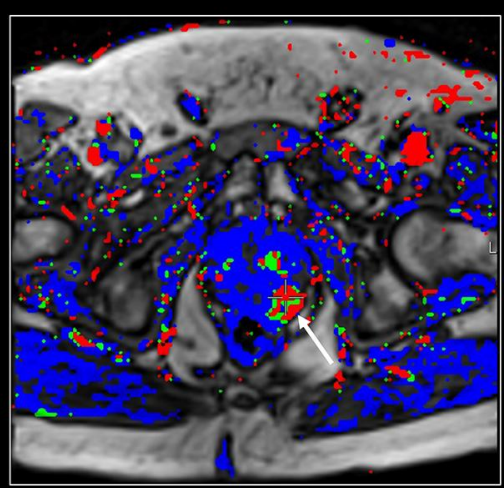

$\mathrm{E}$

Figure 2 Transverse T2-weighted TSE (A), sagittal T2-weighted TSE (B), transverse DWI (C), ADC map (D) and TI-weighted DCE primary perfusion map (E) demonstrate a PIRADS 5 lesion with extracapsular extension and neurovascular bundle involvement on the left side posterolaterally (arrows, a-e). The lesion shows dark T2 signal (A and B) with associated diffusion restriction (C and $\mathbf{D})$ and increased perfusion (E). The lesion is a Gleason $4+4$ tumor.

versus Partin tables alone were 0.73 versus 0.61 for EPE and 0.82 versus 0.75 for SVI. ${ }^{57}$ Therefore, MRI has the potential to improve existing clinical-based models for the prediction of $\mathrm{T} 3$ disease.

\section{Staging of T4 Disease}

T4 prostate cancer constitutes local invasion into structures other than the seminal vesicles such as the bladder, external sphincter, levator muscles, pelvic wall and/or rectum. Most guidelines and policy statements recommend radiation therapy with androgen deprivation therapy for management of T4 prostate cancer due to poor prognosis and high rates of biochemical recurrence. ${ }^{58}$ Accordingly, the detection of $\mathrm{T} 4$ disease prior to surgery is vital for appropriate treatment planning. MRI is successful for pelvic staging (Figure 4).

\section{Regional Staging}

The presence of lymph node metastasis in patients with prostate cancer is of major prognostic significance and guides treatment decision making. Involvement of lymph nodes on pelvic lymph node dissection (PLND) has been associated with increased risk of both progression to distant metastatic disease and cancer-specific mortality. ${ }^{8,59,60}$ Similarly, the number of positive nodes $(>2)$ is one of the strongest predictors available for cancer-specific survival, emphasizing the need to properly risk-stratify patients for possible PLND. ${ }^{60}$ Regardless of T stage, in patients with regional nodal disease the NCCN Prostate Cancer guidelines recommend external beam radiotherapy and androgen deprivation therapy (ADT) or abiraterone and ADT. Current EUA guidelines recommend nodal staging be performed on all patients with pre-biopsy MRI, regardless of risk category, ${ }^{61}$ while a 2020 AUA Policy Statement and updated NCCN guidelines recommend abdominal and pelvic imaging for selected patients (intermediate, high, and very high-risk groups) with nomograms predicting $>10 \%$ risk of nodal metastasis. ${ }^{7,8}$ Unfortunately, the rate of positive lymph metastasis with negative conventional imaging ranges from $0-25 \% .{ }^{62}$ Although advances in technique have improved diagnostic capability of crosssectional imaging in the evaluation of nodal disease, these modalities remain limited due to low sensitivity and PNLD remains the most accurate staging procedure in the detection of lymph node involvement. ${ }^{7,11,60,61}$ 


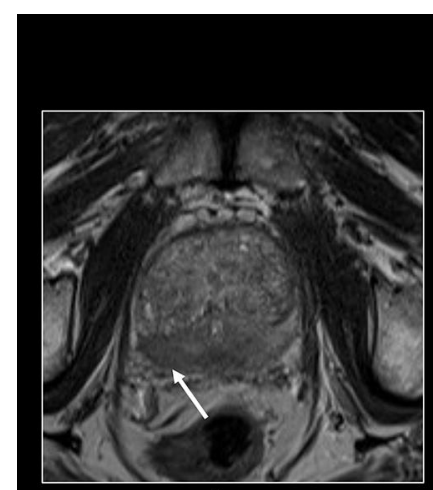

A

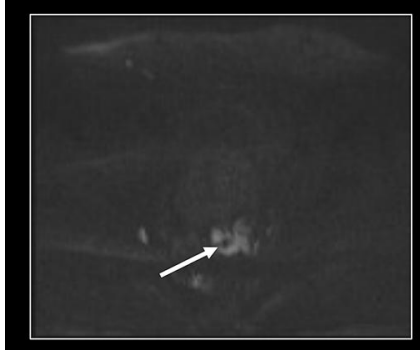

E

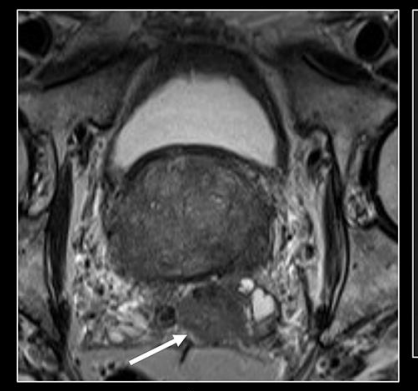

B

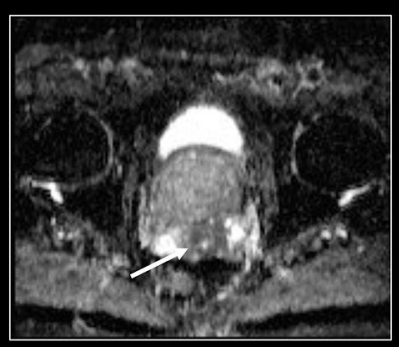

F

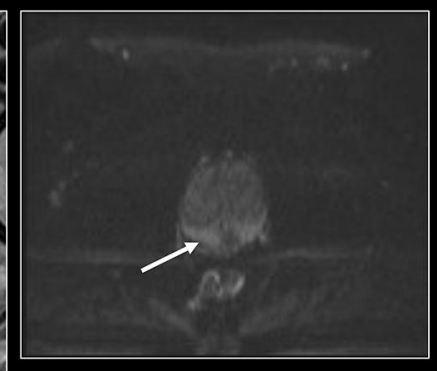

C

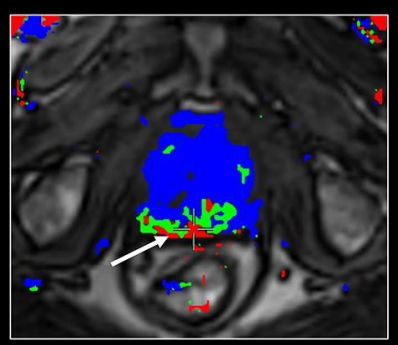

G

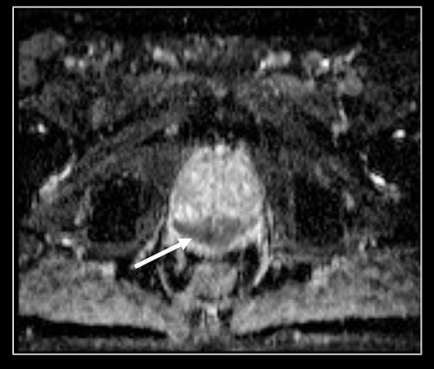

D

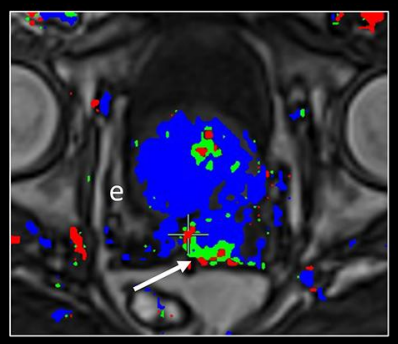

H

Figure 3 TTransverse T2-weighted TSE (A and B), DWI and ADC (C-F), and TI-weighted primary perfusion map (G and $\mathbf{H})$ demonstrate a large infiltrative PIRADS 5 tumor arising from the peripheral zone invading the transitional zone and extending outside the prostate gland and into the seminal vesicles. The tumor is a Gleason $4+4$ tumor with associated extracapsular extension (arrow, A) and seminal vesicle invasion (arrow, B). The tumor is very dark on T2 with associated diffusion restriction and increased perfusion.

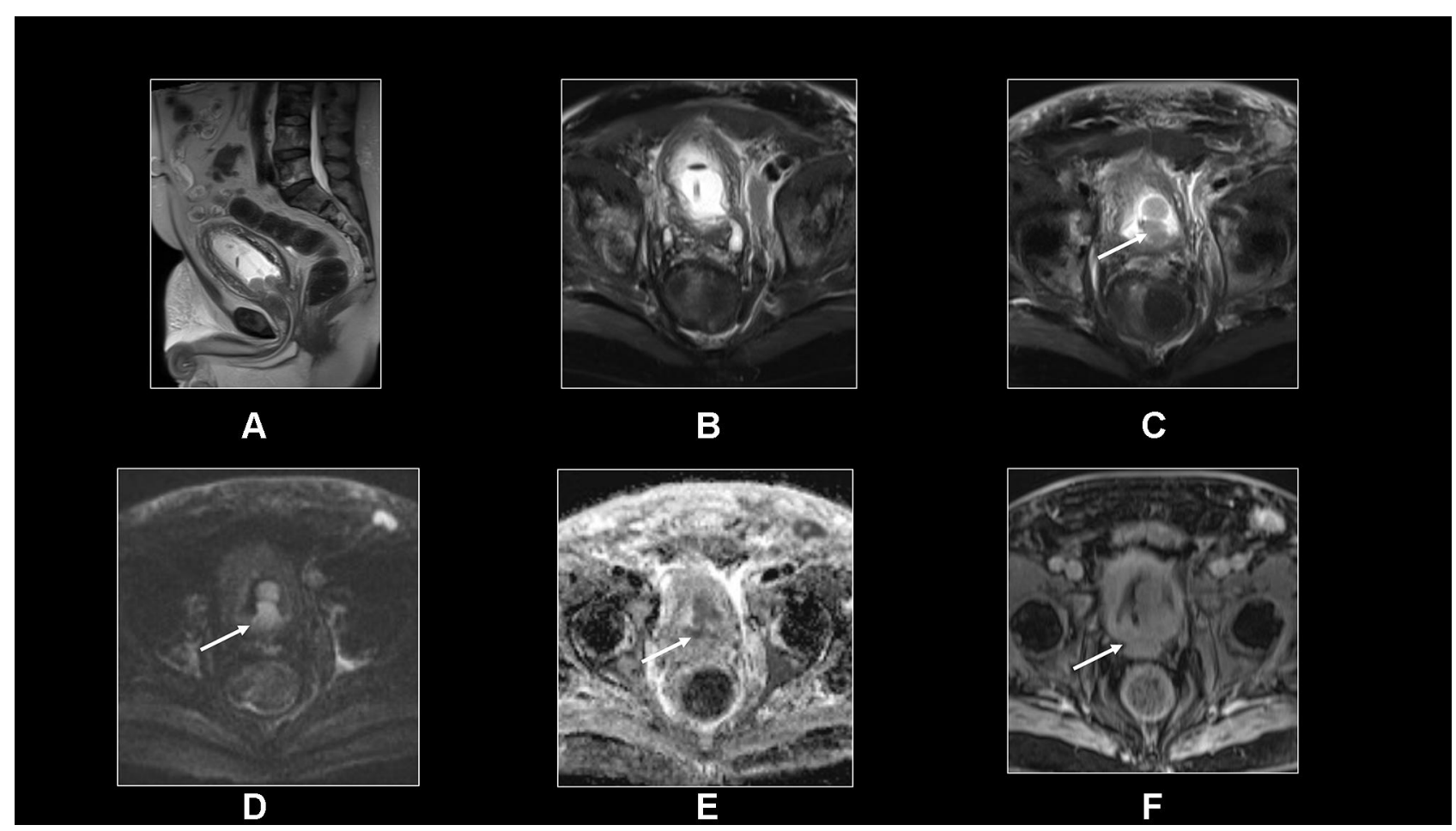

Figure 4 Sagittal T2-SSETSE (A), transverse fat-suppressed T2-weighted SSETSE sequences (B and C), DWI and ADC (D and E) and postgadolinium TI-weighted 3D-GE (F) sequence show a large infiltrative prostate cancer invading the bladder wall (arrows, c-f). 


\section{Current Lymph Node Evaluation}

A designation of $\mathrm{N} 1$ disease comprises a positive lymph node in the obturator, external and internal, or pre-sacral iliac node bundles, which are considered the "regional" nodes. Presence of disease in lymph nodes outside of these four regions upstages the diagnosis to M1. In patients undergoing pre-biopsy MRI, PI-RADS v2 recommends a dedicated sequence for evaluation of lymph nodes that includes extension of study area to level of aortic bifurcation to fully incorporate evaluation of these regional nodal sites.

The detection of abnormal lymph nodes on MRI is currently limited to size, morphology and shape, and enhancement pattern. ${ }^{30}$ Other suggested evaluation criteria include size $>8 \mathrm{~mm}$ (although reported thresholds vary and influence sensitivity/specificity), loss of fatty hilum, rounded shape, low T2W signal relative to primary tumor, and irregular border. ${ }^{61}$ Size alone is an unhelpful criterion for assessment of positive lymph node disease as there is significant overlap between positive and negative nodes, as well as reactive inflammatory changes from unrelated conditions which can produce false positive results. Studies have shown that the majority of positive lymph nodes dissected in extended-PLND (ePLND) following MRI have a short axis diameter of less than $5 \mathrm{~mm}$, below the aforementioned cutoff of $8 \mathrm{~mm} .{ }^{63}$ Further, smaller lymph nodes can harbor micro-metastasis that do not affect node size, leading to incorrect staging. ${ }^{64}$

Suggested ADC values as thresholds for nodal disease detection have similarly demonstrated limited utility, and studies have shown mixed results. Eiber et al demonstrated improved specificity and sensitivity $(85.6 \%, 86.0 \%)$ in prediction of benign vs malignant nodes in prostate cancer using ADC values compared to a size-based analysis with a threshold of $8 \mathrm{~mm}(82.0 \%, 54.4 \%)$. In their assessment of 29 patients, they found a mean ADC lower in metastatic (1.07 $\pm 0.23) \times 10-3 \mathrm{~mm} 2 / \mathrm{s}$ compared to benign $(1.54 \pm 0.25) \times 10-3 \mathrm{~mm} 2 / \mathrm{s} .{ }^{65}$ While other small studies have demonstrated similar findings in regards to ADC differences between benign and malignant nodes, Roy et al found no significant difference in mean ADC between control and malignant lymph nodes in patients with prostate, bladder, penile, and gynecologic malignancies. ADC cut off values are also prone to miss micro-metastasis, and exhibit overlap with other benign conditions such as lipomatosis or follicular hyperplasia. Further, significant reviewer variability exists which limits reproducibility to accurately discriminate between benign and malignant nodes. ${ }^{66}$

\section{MRI vs PLND}

To date, the gold standard for detection of lymph node metastasis remains the ePNLD. Multiple studies have examined the ability of MRI to predict positive lymph nodes in patients undergoing ePNLD, albeit limited in sample size. De Cobelli et al retrospectively assessed 112 patients who underwent both pre-operative 1.5-T MRI and ePNLD and found that PSA value, primary Gleason grade, tumor stage, and tumor volume on MRI were predictive of nodal metastasis on multivariate analysis (sensitivity, specificity, PPV and NPV of their model were $82.6 \%, 96.2 \%, 86.4 \%$ and $94.9 \%$, respectively). By incorporating a cutoff for T3 disease and $>1 \mathrm{cc}$ tumor volume on MRI, they predicted that $55.4 \%$ of their population could have been spared ePNLD while only missing $4.3 \%$ of patients with nodal metastasis. ${ }^{5}$ A large review by Hovels et al determined the pooled sensitivity and specificity of MRI alone in determining patient lymph node status was 0.39 (95\% CI 0.22-0.56) and 0.82 (95\% CI 0.79-0.83). ${ }^{11}$ While MRI can be a valuable tool in the riskstratification of patients requiring ePNLD, its utility in the definitive diagnosis of nodal involvement is limited by poor sensitivity.

\section{MRI vs CT}

The diagnostic value of CT alone in assessment of metastatic lymph nodes for prostate cancer is limited. Similar to MRI, lymph node size is the primary parameter used to assess disease involvement. In a meta-analysis, Hovels et al found pooled sensitivity of $42 \%(95 \% \mathrm{CI}, 26-56 \%)$ and a pooled specificity of $82 \%(95 \% \mathrm{CI}, 79-83 \%)$ for CT in the diagnosis of positive lymph nodes, similar to that of MRI described above. Combination PET/CT has also been suggested as an improved option for nodal evaluation. Walter et al prospectively studied 210 patients with intermediate- and high-risk prostate cancer who underwent [18F]fluoromethylcholine (FCH) PET/CT prior to lymph node dissection between 2008 and 2010. Using histologic evaluation as gold standard comparison, they found FCH PET/CT demonstrated a sensitivity and specificity or $73.2 \%$ and $87.6 \%$, respectively. ${ }^{67}$ A larger meta-analysis incorporating 441 patients from 10 different 
studies found (FCH) PET/CT demonstrated a pooled sensitivity of only $49 \%$, albeit a higher specificity of $95 \%{ }^{68}$ Various other radiotracers have been studied with a wide range of reported findings, but largely PET/CT has demonstrated a limited clinical utility to accurately characterize positive lymph nodes due to a low sensitivity. Theoretically, PET/MRI has distinct advantages including increased resolution and lack of ionizing radiation, however the fundamental limitation, partial volume averaging necessary for PET scans, plagues both PET/CT and PET/MRI. ${ }^{62}$ To date, we are unaware of any studies demonstrating a significant difference in accuracy between PET/MRI and PET/CT. In fact, Freitag et al showed a very high concordance (98.5\%) in a retrospective analysis of suspicious nodes in patients who underwent both Prostate Specific Membrane Antigen (PSMA) PET/MRI and PET/CT. ${ }^{69}$ Ultimately, PET/MRI is limited in detection of abnormal lymph nodes due to low sensitivity, similar to PET/CT.

\section{Metastatic Staging}

While localized prostate cancer has a 5-year survival nearing $100 \%$, presence of distant metastatic disease reduces that figure to roughly $31 \%{ }^{70}$ Prostate cancer can spread to any solid organ, however it tends to show a strong preference towards bone, with some studies finding as high as $80 \%$ of men who died from prostate cancer harboring bone metastasis. ${ }^{70}$ The exact mechanism by which prostate cancer cells preferentially spread to bone are not well defined, but boney metastasis invariably led to a cycle of irregular bone remodeling typically resulting in osteoblastic lesions.

The most recent AUA Guidelines recommend bone scintigraphy in combination with cross sectional imaging for patients with aggressive cancer as defined by D'Amico criteria (cT3a or greater, group grade 4 or 5 , or PSA $\geq 20$ ). ${ }^{71}$ Other factors associated with increased risk or more rapid progression to metastatic disease include a short PSA doubling time, a high Gleason score following histopathology from prostatectomy, and a short interval to biochemical failure. Technetium $99 \mathrm{~m}$ is the most common method for evaluation of bone metastasis, however early metastasis may not be apparent due to poor tracer uptake and lack of bone remodeling. Traditional CT has similarly limited use in bone metastasis, as metastatic lesions can appear similar to fatty marrow. ${ }^{72}$ Recently, Whole-Body (WB) MRI has received attention due to its ability to detect bone metastasis prior to bone remodeling, and therefore prior to detection on bone scintigraphy. ${ }^{61}$

MRI has so far been shown to be a more accurate test in the detection of bone disease compared to conventional bone scintigraphy (BS) and CT. A 2014 meta-analysis of choline-PET/CT, MRI, single-photon emission computed tomography (SPECT), and bone scintigraphy compared detection of M1b lesions in prostate cancer. On a per-patient basis, whole-body MRI demonstrated the highest pooled sensitivity of all modalities at 0.97 (95\% CI: 0.91-0.99), compared to 0.79 (95\% CI: $0.73-0.83$ ) for BS. MRI had a similarly higher sensitivity compared to bone scintigraphy on a per-lesion basis of 0.95 (95\% CI: $0.90-0.97)$ and 0.82 (95\% CI: 0.78-0.85) respectively. ${ }^{73}$ A more recent 2019 meta-analysis by Zhou et al found similar results comparing MRI and bone scintigraphy, with sensitivities of 0.91 and 0.86 , respectively, with both modalities demonstrating high specificity $(>0.95)$ for bone metastasis. ${ }^{74}$ The METastasis Reporting and Data System for Prostate Cancer (MET-RADS-P) has since been designed to facilitate reproducible assessment in WB MRI, and focuses on reporting of presence, location, and extent of disease. ${ }^{72,75}$ Pricolo et al retrospectively found excellent inter-observer reproducibility in the assessment of bone metastasis, with mixed results when assessing other body regions in a sample of 31 patients, ${ }^{76}$ but still requires further validation in clinical trials. Given the increase in popularity of MRI for evaluation of prostatic lesions, WB-MRI offers the prospect of a single-modality imaging for patients with high risk at diagnosis or with concern for recurrence. ${ }^{72}$

Despite promising sensitivity and specificities associated WB-MRI in the detection of bone metastasis, several barriers remain, and WB-MRI has not yet been formally included into guidelines. Systems for standardized reporting have been developed, but remain limited due to sub specialization and training necessary for their interpretation. Similarly, differing MRI protocols and need for various MRI coils are resource intensive and limit WB-MRI use outside of specialized medical centers, although it should be acknowledged that MET-RADS-P techniques can be implemented on standard MRI machines. ${ }^{72}$ Finally, WB-MRI is associated with higher costs compared to BS which have the potential to contribute to patient financial toxicity. 


\section{Future Directions}

Previously utilized primarily with CT scans, the integration of PET and MRI scanners has introduced a new potential of multi-modal imaging, particularly in the detection of nodal and metastatic disease for men with high-risk prostate cancer and concern for recurrence. 18F-choline, 11C-choline, 11C-Acetate, 18F-Fluciclovine have all shown promise in prostate cancer imaging, however the marker demonstrating the most potential when incorporated with MRI has been ProstateSpecific Membrane Antigen (PSMA) ${ }^{77}$ PSMA has shown promise for identification of both regional and metastatic disease in high risk patients and those with concern for with biochemical recurrence. PSMA is a transmembrane protein that particularly upregulated in prostate cancer cells and in metastatic disease, although it is also expressed in salivary glands, lacrimal glands, small intestine, renal tubules, and neo-vasculature of the thyroid. ${ }^{64,72,78}$ PSMA expression exists in benign prostate gland cells, however in cancer cells PSMA is more widely available on the basal layer making this target much more available for PET targeting, and increased expression is correlated with higher tumor grade. 68GPSMA has been the most widely used and studied marker thus far. Maurer et al compared 130 patients with intermediate or high-risk prostate cancer who underwent either 68Ga-PSMA PET/MRI or PET/CT prior to prostatectomy and PLND for detection of nodal disease. On a per patient analysis, incorporation of PSMA PET/MRI or PET/CT showed a sensitivity and specificity of $65.9 \%$ and $98.9 \%$, respectively, compared to $43.9 \%, 85.4 \%$ for CT or MRI in absence of PET. ${ }^{79}$ Han et al further questioned the clinical utility of PSMA PET/CT or PET/MRI, and found in a systematic review that use of 68Ga-PSMA in 1163 patients across 15 studies resulted in a pooled proportion of management change of 54\% (95\% CI 47-60\%), suggesting a large effect of PSMA incorporated PET imaging on clinical decision making in patients with prostate cancer.

An additional role of PSMA has been suggested in patients undergoing repeat imaging following biochemical failure, defined as a PSA value of over $0.2 \mathrm{ng} / \mathrm{mL}$ at two different time points. In a retrospective analysis of 117 patients with hormone-naïve biochemical failure (BCF), Grubmuller et al found PSMA positive lesions using PET/CT or PET/MRI in $100(85.5 \%)$ of patients including a $65 \%$ detection rate for sub-set of patients with PSA of 0.2 to $0.5 \mathrm{ng} / \mathrm{mL}$. Notably, PSMA incorporation identified uptake in $67(67 \%)$ patients where MRI or CT alone failed to identify any suspicious morphologic characteristics. ${ }^{80}$ Few direct comparisons exist between PSMA PET/CT and PSMA PET/MRI, however Freitag et al found a 98.5\% concordance rate between PSMA PET/CT and PET/MRI when evaluating 64 lymph nodes. Two PET-positive bone metastasis could not be confirmed morphologically using CT, but could be confirmed with MRI. ${ }^{69}$ Given the large volume of literature focused primarily on PSMA-PET/CT, further study is needed to fully define the role of PSMA-PET/MRI in patients with high risk or recurrent prostate cancer.

\section{Conclusions}

In this narrative review we explored the current opinions for use of MRI in staging prostate cancer. Current guidelines vary significantly regarding the use of MRI for staging. However, many guidelines recommend cross-sectional imaging, including MRI, for high-risk disease. MRI has high specificity for diagnosing EPE, SVI and LN metastases, however its sensitivity remains limited. Therefore, when considered in the context of staging variables such as PSA and clinical stage, MRI has the potential to impact the decision to perform nerve sparing prostatectomy, extend ADT duration, or radiation field. MRI has been shown to perform reasonably to evaluate bone metastases, however guidelines still endorse the use of bone scintigraphy. Emerging technology, such as novel PET radiotracers and combining MRI with PET, have the potential to improve the accuracy of prostate cancer staging.

\section{Disclosure}

The authors report no conflicts of interest in this work.

\section{References}

1. Siegel RL, Miller KD, Fuchs HE, Jemal A. Cancer statistics, 2021. CA Cancer J Clin. 2021;71(1):7-33.

2. Cooperberg MR, Lubeck DP, Mehta SS, Carroll PR. Time trends in clinical risk stratification for prostate cancer: implications for outcomes (data from CaPSURE). J Urol. 2003;170(6 Pt 2):S26-27. 
3. Bjurlin MA, Rosenkrantz AB, Beltran LS, Raad RA, Taneja SS. Imaging and evaluation of patients with high-risk prostate cancer. Nat Rev Urol. 2015;12(11):617-628.

4. Rayn KN, Bloom JB, Gold SA, et al. Added value of multiparametric magnetic resonance imaging to clinical nomograms for predicting adverse pathology in prostate cancer. J Urol. 2018;200(5):1041-1047.

5. Brembilla G, Dell'Oglio P, Stabile A, et al. Preoperative multiparametric MRI of the prostate for the prediction of lymph node metastases in prostate cancer patients treated with extended pelvic lymph node dissection. Eur Radiol. 2018;28(5):1969-1976.

6. Fulgham PF, Rukstalis DB, Turkbey IB, et al. AUA policy statement on the use of multiparametric magnetic resonance imaging in the diagnosis, staging and management of prostate cancer. J Urol. 2017;198(4):832-838.

7. Bjurlin MA, Carroll PR, Eggener S, et al. Update of the Standard Operating Procedure on the Use of Multiparametric Magnetic Resonance Imaging for the Diagnosis, Staging and Management of Prostate Cancer. J Urol. 2020;203(4):706-712.

8. Kirkby E. NCCN clinical practice guidelines in Oncology prostate cancer version 2.2021. Nat Comprehen Cancer Net. 2021.

9. Mottet N, van den Bergh RCN, Briers E, et al. EAU-EANM-ESTRO-ESUR-SIOG Guidelines on Prostate Cancer-2020 Update. Part 1: screening, Diagnosis, and Local Treatment with Curative Intent. Eur Urol. 2021;79(2):243-262.

10. Sanda MG, Cadeddu JA, Kirkby E, et al. Clinically Localized Prostate Cancer: AUA/ASTRO/SUO Guideline. Part I: risk Stratification, Shared Decision Making, and Care Options. J Urol. 2018;199(3):683-690.

11. Hovels AM, Heesakkers RA, Adang EM, et al. The diagnostic accuracy of CT and MRI in the staging of pelvic lymph nodes in patients with prostate cancer: a meta-analysis. Clin Radiol. 2008;63(4):387-395.

12. Pinaquy JB, De Clermont-galleran H, Pasticier G, et al. Comparative effectiveness of [(18) F]-fluorocholine PET-CT and pelvic MRI with diffusion-weighted imaging for staging in patients with high-risk prostate cancer. Prostate. 2015;75(3):323-331.

13. Heck MM, Souvatzoglou M, Retz M, et al. Prospective comparison of computed tomography, diffusion-weighted magnetic resonance imaging and $[11 \mathrm{C}]$ choline positron emission tomography/computed tomography for preoperative lymph node staging in prostate cancer patients. Eur J Nucl Med Mol Imaging. 2014;41(4):694-701.

14. Van den Bergh L, Lerut E, Haustermans K, et al. Final analysis of a prospective trial on functional imaging for nodal staging in patients with prostate cancer at high risk for lymph node involvement. Urol Oncol. 2015;33(3):109 e123-131.

15. Perera M, Papa N, Roberts M, et al. Gallium-68 Prostate-specific Membrane Antigen Positron Emission Tomography in Advanced Prostate Cancer-Updated Diagnostic Utility, Sensitivity, Specificity, and Distribution of Prostate-specific Membrane Antigen-avid Lesions: a Systematic Review and Meta-analysis. Eur Urol. 2020;77(4):403-417.

16. van Kalmthout LWM, van Melick HHE, Lavalaye J, et al. Prospective Validation of Gallium-68 Prostate Specific Membrane Antigen-Positron Emission Tomography/Computerized Tomography for Primary Staging of Prostate Cancer. J Urol. 2020;203(3):537-545.

17. Stanzione A, Ponsiglione A, Cuocolo R, et al. Abbreviated protocols versus multiparametric MRI for assessment of extraprostatic extension in prostatic carcinoma: a multireader study. Anticancer Res. 2019;39(8):4449-4454.

18. Christophe C, Montagne S, Bourrelier S, et al. Prostate cancer local staging using biparametric MRI: assessment and comparison with multiparametric MRI. Eur J Radiol. 2020;132:109350.

19. Caglic I, Sushentsev N, Shah N, et al. Comparison of biparametric versus multiparametric prostate MRI for the detection of extracapsular extension and seminal vesicle invasion in biopsy naïve patients. Eur J Radiol. 2021;2:109804.

20. Cuocolo R, Stanzione A, Ponsiglione A, et al. Prostate MRI technical parameters standardization: a systematic review on adherence to PI-RADSv2 acquisition protocol. Eur J Radiol. 2019;120:108662.

21. Chatterjee A, Harmath C, Oto A. New prostate MRI techniques and sequences. Abdom Radiol. 2020;45(12):4052-4062.

22. Dickinson L, Ahmed HU, Allen C, et al. Magnetic resonance imaging for the detection, localisation, and characterisation of prostate cancer: recommendations from a European consensus meeting. Eur Urol. 2011;59(4):477-494.

23. Barentsz JO, Richenberg J, Clements R, et al. ESUR prostate MR guidelines 2012. Eur Radiol. 2012;22(4):746-757.

24. Turkbey B, Rosenkrantz AB, Haider MA, et al. Prostate Imaging Reporting and Data System Version 2.1: 2019 Update of Prostate Imaging Reporting and Data System Version 2. Eur Urol. 2019;76(3):340-351.

25. Westphalen AC, McCulloch CE, Anaokar JM, et al. Variability of the Positive Predictive Value of PI-RADS for Prostate MRI across 26 Centers: experience of the Society of Abdominal Radiology Prostate Cancer Disease-focused Panel. Radiology. 2020;296(1):76-84.

26. Brizmohun appayya M, Adshead J, Ahmed HU, et al. National implementation of multi-parametric magnetic resonance imaging for prostate cancer detection - recommendations from a UK consensus meeting. BJU Int. 2018;122(1):13-25.

27. UK NGUT. Prostate cancer: Diagnosis and management. 2019.

28. Latifoltojar A, Appayya MB, Barrett T, Punwani S. Similarities and differences between Likert and PIRADS v2.1 scores of prostate multiparametric MRI: a pictorial review of histology-validated cases. Clin Radiol. 2019;74(11):895e891-895 e815.

29. Rosenkrantz AB, Lim RP, Haghighi M, Somberg MB, Babb JS, Taneja SS. Comparison of interreader reproducibility of the prostate imaging reporting and data system and Likert scales for evaluation of multiparametric prostate MRI. AJR Am J Roentgenol. 2013;201(4):W612-618.

30. Renard-Penna R, Mozer P, Cornud F, et al. Prostate Imaging Reporting and Data System and Likert Scoring System: multiparametric MR Imaging Validation Study to Screen Patients for Initial Biopsy. Radiology. 2015;275(2):458-468.

31. Khoo CC, Eldred-Evans D, Peters M, et al. Likert vs PI-RADS v2: a comparison of two radiological scoring systems for detection of clinically significant prostate cancer. BJU Int. 2020;125(1):49-55.

32. Shin T, Smyth TB, Ukimura O, et al. Diagnostic accuracy of a five-point Likert scoring system for magnetic resonance imaging (MRI) evaluated according to results of MRI/ultrasonography image-fusion targeted biopsy of the prostate. BJU Int. 2018;121(1):77-83.

33. Eifler JB, Feng Z, Lin BM, et al. An updated prostate cancer staging nomogram (Partin tables) based on cases from 2006 to 2011. BJU Int. 2013;111(1):22-29.

34. Augustin H, Fritz GA, Ehammer T, Auprich M, Pummer K. Accuracy of 3-Tesla magnetic resonance imaging for the staging of prostate cancer in comparison to the Partin tables. Acta Radiol. 2009;50(5):562-569.

35. Schiavina R, Bianchi L, Borghesi M, et al. MRI Displays the Prostatic Cancer Anatomy and Improves the Bundles Management Before Robot-Assisted Radical Prostatectomy. J Endourol. 2018;32(4):315-321.

36. Panebianco V, Salciccia S, Cattarino S, et al. Use of multiparametric MR with neurovascular bundle evaluation to optimize the oncological and functional management of patients considered for nerve-sparing radical prostatectomy. J Sex Med. 2012;9(8):2157-2166. 
37. Jaderling F, Akre O, Aly M, et al. Preoperative staging using magnetic resonance imaging and risk of positive surgical margins after prostate-cancer surgery. Prostate Cancer Prostatic Dis. 2019;22(3):391-398.

38. Rud E, Baco E, Klotz D, et al. Does preoperative magnetic resonance imaging reduce the rate of positive surgical margins at radical prostatectomy in a randomised clinical trial? Eur Urol. 2015;68(3):487-496.

39. Marenco J, Orczyk C, Collins T, Moore C, Emberton M. Role of MRI in planning radical prostatectomy: what is the added value? World J Urol. 2019;37(7):1289-1292.

40. de Rooij M, Hamoen EH, Witjes JA, Barentsz JO, Rovers MM. Accuracy of Magnetic Resonance Imaging for Local Staging of Prostate Cancer: a Diagnostic Meta-analysis. Eur Urol. 2016;70(2):233-245.

41. Boesen L, Chabanova E, Logager V, Balslev I, Mikines K, Thomsen HS. Prostate cancer staging with extracapsular extension risk scoring using multiparametric MRI: a correlation with histopathology. Eur Radiol. 2015;25(6):1776-1785.

42. Kayat Bittencourt L, Litjens G. Prostate cancer: the European society of urogenital radiology prostate imaging reporting and data system criteria for predicting extraprostatic extension by using 3-T multiparametric MR imaging. Radiology. 2015;276(2):479-489.

43. Mehralivand S, Shih JH, Harmon S, et al. A Grading System for the Assessment of Risk of Extraprostatic Extension of Prostate Cancer at Multiparametric MRI. Radiology. 2019;290(3):709-719.

44. Reisaeter LAR, Halvorsen OJ, Beisland C, et al. Assessing Extraprostatic Extension with Multiparametric MRI of the Prostate: mehralivand Extraprostatic Extension Grade or Extraprostatic Extension Likert Scale? Radiol Imaging Cancer. 2020;2(1):e190071.

45. Caglic I, Povalej Brzan P, Warren AY, Bratt O, Shah N, Barrett T. Defining the incremental value of 3D T2-weighted imaging in the assessment of prostate cancer extracapsular extension. Eur Radiol. 2019;29(10):5488-5497.

46. Rosenkrantz AB, Shanbhogue AK, Wang A, Kong MX, Babb JS, Taneja SS. Length of capsular contact for diagnosing extraprostatic extension on prostate MRI: assessment at an optimal threshold. J Magn Reson Imaging. 2016;43(4):990-997.

47. Baco E, Rud E, Vlatkovic L, et al. Predictive value of magnetic resonance imaging determined tumor contact length for extracapsular extension of prostate cancer. J Urol. 2015;193(2):466-472.

48. Woo S, Kim SY, Cho JY, Kim SH. Length of capsular contact on prostate MRI as a predictor of extracapsular extension: which is the most optimal sequence? Acta Radiol. 2017;58(4):489-497.

49. Shieh AC, Guler E, Ojili V, et al. Extraprostatic extension in prostate cancer: primer for radiologists. Abdom Radiol. 2020;45(12):4040-4051.

50. Rud E, Diep L, Baco E. A prospective study evaluating indirect MRI-signs for the prediction of extraprostatic disease in patients with prostate cancer: tumor volume, tumor contact length and tumor apparent diffusion coefficient. World J Urol. 2018;36(4):629-637.

51. Lim C, Flood TA, Hakim SW, et al. Evaluation of apparent diffusion coefficient and MR volumetry as independent associative factors for extra-prostatic extension (EPE) in prostatic carcinoma. J Magn Reson Imaging. 2016;43(3):726-736.

52. Potter SR, Epstein JI, Partin AW. Seminal vesicle invasion by prostate cancer: prognostic significance and therapeutic implications. Rev Urol. 2000;2(3):190-195.

53. Wang L, Hricak H, Kattan MW, et al. Prediction of seminal vesicle invasion in prostate cancer: incremental value of adding endorectal MR imaging to the Kattan nomogram. Radiology. 2007;242(1):182-188.

54. Grivas N, Hinnen K, de Jong J, et al. Seminal vesicle invasion on multi-parametric magnetic resonance imaging: correlation with histopathology. Eur J Radiol. 2018;98:107-112.

55. Riney JC, Sarwani NE, Siddique S, Raman JD. Prostate magnetic resonance imaging: the truth lies in the eye of the beholder. Urol Oncol. 2018;36 (4):159e151-159 e155.

56. Ohori M, Scardino PT, Lapin SL, Seale-Hawkins C, Link J, Wheeler TM. The mechanisms and prognostic significance of seminal vesicle involvement by prostate cancer. Am J Surg Pathol. 1993;17(12):1252-1261.

57. Morlacco A, Sharma V, Viers BR, et al. The Incremental Role of Magnetic Resonance Imaging for Prostate Cancer Staging before Radical Prostatectomy. Eur Urol. 2017;71(5):701-704.

58. Ranasinghe WKB, Reichard CA, Bathala T, Chapin BF. Management of cT4 Prostate Cancer. Eur Urol Focus. 2020;6(2):221-226.

59. Gervasi LA, Mata J, Easley JD, et al. Prognostic significance of lymph nodal metastases in prostate cancer. J Urol. 1989;142(2 Pt 1):332-336.

60. Briganti A, Blute ML, Eastham JH, et al. Pelvic lymph node dissection in prostate cancer. Eur Urol. 2009;55(6):1251-1265.

61. Caglic I, Kovac V, Barrett T. Multiparametric MRI - local staging of prostate cancer and beyond. Radiol Oncol. 2019;53(2):159-170.

62. Thoeny HC, Barbieri S, Froehlich JM, Turkbey B, Choyke PL. Functional and Targeted Lymph Node Imaging in Prostate Cancer: current Status and Future Challenges. Radiology. 2017;285(3):728-743.

63. Thoeny HC, Froehlich JM, Triantafyllou M, et al. Metastases in normal-sized pelvic lymph nodes: detection with diffusion-weighted MR imaging. Radiology. 2014;273(1):125-135.

64. Sankineni S, Brown AM, Fascelli M, et al. Lymph node staging in prostate cancer. Curr Urol Rep. 2015;16(5):30.

65. Eiber M, Beer AJ, Holzapfel K, et al. Preliminary results for characterization of pelvic lymph nodes in patients with prostate cancer by diffusion-weighted MR-imaging. Invest Radiol. 2010;45(1):15-23.

66. Kwee TC, Takahara T, Luijten PR, Nievelstein RA. ADC measurements of lymph nodes: inter- and intra-observer reproducibility study and an overview of the literature. Eur J Radiol. 2010;75(2):215-220.

67. Poulsen MH, Bouchelouche K, Hoilund-Carlsen PF, et al. [18F]fluoromethylcholine ( $\mathrm{FCH})$ positron emission tomography/computed tomography (PET/CT) for lymph node staging of prostate cancer: a prospective study of 210 patients. BJU Int. 2012;110(11):1666-1671.

68. Bouchelouche K, Turkbey B, Choyke PL, PET PSMA. Radionuclide Therapy in Prostate Cancer. Semin Nucl Med. 2016;46(6):522-535.

69. Freitag MT, Radtke JP, Hadaschik BA, et al. Comparison of hybrid (68) Ga-PSMAPET/MRI and (68) Ga-PSMAPET/CT in the evaluation of lymph node and bone metastases of prostate cancer. Eur J Nucl Med Mol Imaging. 2016;43(1):70-83.

70. Jin JK, Dayyani F, Gallick GE. Steps in prostate cancer progression that lead to bone metastasis. Int J Cancer. 2011;128(11):2545-2561.

71. Lowrance WT, Breau RH, Chou R, et al. Advanced prostate cancer: AUA/ASTRO/SUO guideline part I. $J$ Urol. 2021;205(1):14-21.

72. Perez-Lopez R, Tunariu N, Padhani AR, et al. Imaging Diagnosis and Follow-up of Advanced Prostate Cancer: clinical Perspectives and State of the Art. Radiology. 2019;292(2):273-286.

73. Shen G, Deng H, Hu S, Jia Z. Comparison of choline-PET/CT, MRI, SPECT, and bone scintigraphy in the diagnosis of bone metastases in patients with prostate cancer: a meta-analysis. Skeletal Radiol. 2014;43(11):1503-1513. 
74. Zhou J, Gou Z, Wu R, Yuan Y, Yu G, Zhao Y. Comparison of PSMA-PET/CT, choline-PET/CT, NaF-PET/CT, MRI, and bone scintigraphy in the diagnosis of bone metastases in patients with prostate cancer: a systematic review and meta-analysis. Skeletal Radiol. 2019;48(12):1915-1924.

75. Turkbey B, Choyke PL. Prostate cancer: birth of a standard: MET-RADS-P for metastatic prostate cancer. Nat Rev Urol. 2016;13(10):568-570.

76. Pricolo P, Ancona E, Summers P, et al. Whole-body magnetic resonance imaging (WB-MRI) reporting with the METastasis Reporting and Data System for Prostate Cancer (MET-RADS-P): inter-observer agreement between readers of different expertise levels. Cancer Imaging. 2020;20 (1):77.

77. Hoffmann MA, Wieler HJ, Baues C, Kuntz NJ, Richardsen I, Schreckenberger M. The Impact of 68Ga-PSMA PET/CT and PET/MRI on the Management of Prostate Cancer. Urology. 2019;130:1-12.

78. Bonkhoff $\mathrm{H}$. Role of the basal cells in premalignant changes of the human prostate: a stem cell concept for the development of prostate cancer. Eur Urol. 1996;30(2):201-205.

79. Maurer T, Gschwend JE, Rauscher I, et al. Diagnostic Efficacy of (68) Gallium-PSMAPositron Emission Tomography Compared to Conventional Imaging for Lymph Node Staging of 130 Consecutive Patients with Intermediate to High Risk Prostate Cancer. J Urol. 2016;195(5):1436-1443.

80. Grubmuller B, Baltzer P, D'Andrea D, et al. (68)Ga-PSMA 11 ligand PET imaging in patients with biochemical recurrence after radical prostatectomy - diagnostic performance and impact on therapeutic decision-making. Eur J Nucl Med Mol Imaging. 2018;45(2):235-242.

81. Muehlematter UJ, Burger IA, Becker AS, et al. Diagnostic Accuracy of Multiparametric MRI versus (68) Ga-PSMA-11PET/MRI for Extracapsular Extension and Seminal Vesicle Invasion in Patients with Prostate Cancer. Radiology. 2019;293(2):350-358.

82. Boesen L. Multiparametric MRI in detection and staging of prostate cancer. Dan Med J. 2017;64:2.

83. Bai K, Sun Y, Li W, Zhang L. Apparent diffusion coefficient in extraprostatic extension of prostate cancer: a systematic review and diagnostic meta-analysis. Cancer Manag Res. 2019;11:3125-3137.

84. Zhang F, Liu CL, Chen Q, Shao SC, Chen SQ. Accuracy of multiparametric magnetic resonance imaging for detecting extracapsular extension in prostate cancer: a systematic review and meta-analysis. Br J Radiol. 2019;92(1104):20190480.

85. Tirumani SH, Suh CH, Kim KW, Shinagare AB, Ramaiya NH, Fennessy FM. Head-to-head comparison of prostate MRI using an endorectal coil versus a non-endorectal coil: meta-analysis of diagnostic performance in staging T3 prostate cancer. Clin Radiol. 2020;75(2):157e159-157 e119.

86. Davis R, Salmasi A, Koprowski C, et al. Accuracy of Multiparametric Magnetic Resonance Imaging for Extracapsular Extension of Prostate Cancer in Community Practice. Clin Genitourin Cancer. 2016;14(6):e617-e622.

87. Cerantola Y, Valerio M, Kawkabani Marchini A, Meuwly JY, Jichlinski P. Can 3T multiparametric magnetic resonance imaging accurately detect prostate cancer extracapsular extension? Can Urol Assoc J. 2013;7(11-12):E699-703.

88. Dominguez C, Plata M, Catano JG, et al. Diagnostic accuracy of multiparametric magnetic resonance imaging in detecting extracapsular extension in intermediate and high - risk prostate cancer. Int Braz J Urol. 2018;44(4):688-696.

89. Gaunay GS, Patel V, Shah P, et al. Multi-parametric MRI of the prostate: factors predicting extracapsular extension at the time of radical prostatectomy. Asian Journal of Urology. 2017;4(1):31-36.

90. Feng TS, Sharif-Afshar AR, Wu J, et al. Multiparametric MRI Improves Accuracy of Clinical Nomograms for Predicting Extracapsular Extension of Prostate Cancer. Urology. 2015;86(2):332-337.

91. Hegde JV, Chen MH, Mulkern RV, Fennessy FM, D'Amico AV, Tempany CM. Preoperative 3-Tesla multiparametric endorectal magnetic resonance imaging findings and the odds of upgrading and upstaging at radical prostatectomy in men with clinically localized prostate cancer. Int $J$ Radiat Oncol Biol Phys. 2013;85(2):e101-107.

92. Lee H, Kim CK, Park BK, et al. Accuracy of preoperative multiparametric magnetic resonance imaging for prediction of unfavorable pathology in patients with localized prostate cancer undergoing radical prostatectomy. World J Urol. 2017;35(6):929-934.

93. Lee T, Hoogenes J, Wright I, Matsumoto ED, Shayegan B. Utility of preoperative 3 Tesla pelvic phased-array multiparametric magnetic resonance imaging in prediction of extracapsular extension and seminal vesicle invasion of prostate cancer and its impact on surgical margin status: experience at a Canadian academic tertiary care centre. Can Urol Assoc J. 2017;11(5):E174-E178.

94. Toner L, Papa N, Perera M, et al. Multiparametric magnetic resonance imaging for prostate cancer-a comparative study including radical prostatectomy specimens. World J Urol. 2017;35(6):935-941.

95. Leibovici D, Kamat AM, Do KA, et al. Transrectal ultrasound versus magnetic resonance imaging for detection of rectal wall invasion by prostate cancer. Prostate. 2005;62(1):101-104.

Cancer Management and Research

Dovepress

Publish your work in this journal

Cancer Management and Research is an international, peer-reviewed open access journal focusing on cancer research and the optimal use of preventative and integrated treatment interventions to achieve improved outcomes, enhanced survival and quality of life for the cancer patient. The manuscript management system is completely online and includes a very quick and fair peer-review system, which is all easy to use. Visit http://www.dovepress.com/testimonials.php to read real quotes from published authors.

Submit your manuscript here: https://www.dovepress.com/cancer-management-and-research-journal 